\title{
The Research on College Physics Curriculum System Based on General Education
}

\author{
Wang Le-xin, Zhu Wen-xia, Wang Chang, Guan Xiao-yan \\ College of Science, Heilongiiang Bayi Agricultural University, Daqing, China
}

Email address:

wanglexin@126.com (Wang Le-xin),270335673@qq.com (Zhu Wen-xia), changwangbayi@163.com (Wang Chang), 1220495432@qq.com (Guan Xiao-yan)

\section{To cite this article:}

Wang Le-xin, Zhu Wen-xia, Wang Chang, Guan Xiao-yan. The Research on College Physics Curriculum System Based on General Education. Science Journal of Education. Vol. 4, No. 2, 2016, pp. 53-56. doi: 10.11648/j.sjedu.20160402.16

Received: February 2, 2016; Accepted: March 31, 2016; Published: April 9, 2016

\begin{abstract}
In order to perform the principle of general education, play a related role between humanities, science and technology and combine the learnt knowledge and quality training, human spirit and scientific ideas, we develop college physics series successor curriculum courses under the leadership of modern educational ideas after students have finished college physics course. Aiming at cultivating creative and qualified personnel with broad vision and creativity, students need to dabble in different disciplines and foster their scientific literacy, humanistic quality and innovative consciousness by means of establishing a quality education for interdisciplinary orientation to pass elective system in imperceptible culture. College physical curriculum system with agriculture and forestry universities characteristics has been initially established, which plays an exemplary and popularized role in Chinese congener schools.
\end{abstract}

Keywords: General Education, Electives, College Physical, Curriculum System

\section{Introduction}

Since the new century, China attaches great importance to education research and practice of general education, combined with China's national conditions for a new attempt [1 3]. Liberal is science, humanities, arts quality education, in essence, Liberal Studies is an educational philosophy, not a special ability. Modern university education in general education goals, not just to develop sublime and ensure the spread of humanist educational tradition, more importantly, is to train students an awareness and attitudes-both insight into the essence of scientific thinking, without exclusion of humanism essence; pay attention to both the development and application of science and technology, without neglecting the eternal pursuit of the sublime. Modern university general education pathway has changed from the tradition to emphasizing the humanities and social science courses, mainly to put attention and promotion of modern university education in the humanities and science courses into the direction of the combination or fusion. And General connotation adaption, the fundamental task of the University is to train all-round development of talent, improve students' moral qualities, knowledge and practical ability. Students not only have strong professional knowledge, but also have a more profound cultural knowledge and technological knowledge, so as to adapt to the needs of society, being conducive to innovation in their work, and promote the cause of China's modernization drive rapid development $[4,5]$.

The current emphasis on professionalism in university education, while ignoring the intersection among different disciplines penetration, is likely to cause students to a narrow range of knowledge, logical thinking and expression, which is weak and other defects $[6,7]$. As the current quality of university education for the overall development of students' negative, the full implementation of general education is particularly necessary. "CPC Central Committee and State Council on deepening education reform and promoting quality education decision" clearly states, "Higher education should focus on cultivating students' innovation ability, practical ability and entrepreneurial ability, a general increasing in the humanities and sciences college quality". Teaching content immediately develops, and the idea will gradually penetrate into the general education personnel training mode, which will improve the students' creativity, overall quality, and the development of their personality as 
personnel training objectives; the training to adapt to social development, "people" education concept has been integrated into teaching them. In the view of Chinese and international experience, combined with my school characteristics and teaching courses to expand students' basic knowledge, strengthening quality education, promoting blend of Arts and cultivate innovative thinking. It is necessary to finish college student studying physics course, building physics successor series courses in general education, which has made preliminary exploration [8].

\section{China Agricultural University Physics Course Series System Construction}

We have investigated China agricultural university physics course series system construction by questionnaires and online query. Survey of Tsinghua University, Peking University, including 24 engineering colleges and 20 Chinese agricultural and forestry colleges, the results shows the surveyed Chinese 20 forestry institutions, only nine schools opened one or two with the University physics-related elective courses, which opened in Dalian Fisheries University "in the use of computers in physics, modern physics knowledge and high-tech, laser theory and application of science and technology photography, electromagnetic biological effects and applications" and five elective courses. Survey of Tsinghua University, Peking University, including 24 non-agricultural and forestry engineering colleges, there are seven colleges opened a physics-related elective course. Only two institutions do not offer elective courses, including Tsinghua University, Nanjing Audit University, Xi'an Jiaotong University, Shanghai Second Polytechnic University, Nanjing University of Aeronautics and Astronautics, Armored Force Engineering Institute and other six institutions opened four more physical class elective courses. The Survey shows that engineering colleges pay more attention to general education than the agricultural institutions, focusing on students' knowledge of different disciplines cross between penetration and Humane Education. Suggested Forestry College Teachers according to their strengths and interests to open elective courses, the most exciting physics, the most exciting, the most memorable content to speak out, to attract more students interested in physics and physical knowledge. Formation plus compulsory elective curriculum, physical education should play a university science education and humanities education as the dual task, so that students received physical education not only have a certain scientific literacy, but also have some human qualities. Therefore students have a strong expertise with a more profound cultural knowledge and technological knowledge, so as to adapt to the needs of society, being conducive to innovation in their work, and to promote the cause of China's modernization drive rapid development.

\section{Broaden the Base, Arts and Penetration, Enhance Students' Cultural Quality Education}

Guided by modern education and the principle of general education, students are cultivated with the purpose of development around knowledge, quality, ability, and morality. After completing college physics, students will be taught by a new teaching system, an expansion of previous study, with physics education as the basis, which aims at enhancing students 'scientific and humanistic quality, training students' innovative ability. Through extensive research, elective courses, namely, "science and photography and photographic art", "physics and art", "Introduction to modern science and technology" are offered. Students are trained integrate physical and humanistic spirit together. The enhancement of the cultural quality education by broadening the base and adding Arts aims at overcoming the narrowness of professional education. Physics Education is supposed to play a unique role in both Humanistic Education and Scientific Education.

Agricultural universities in the country opened the first "Physical and Art" elective, teaching content was mainly artists and physicists, explaining the parallel perspective image of the universe and understanding of the process of establishing the basic form of motion of matter knowledge. The common purpose of science and art is an innovative which means to evoke consciousness or subconsciousness and emotional resonance of nature, but the "language" they use is different [9]. One of the aims of this course is to break between the "language" barrier analysis and comparison of their sense of innovation and to think methods in common; We hope to achieve the purpose of developing students' science and humanities qualities and creative thinking. In line with modern educational philosophy, "Physics and Art" is a curriculum with important innovative ideas. In teaching, we also pointed out that the artists understanding of nature is not able to establish a complete picture of science, and this understanding is not the test of experiment, truth and fallacy coexist. Art is not physical, nor is speculative science.

Promoting quality education in cultivating innovative talents situation, the creation of "technology Photography and Photographic Art" course, takes full advantage of the features of the subject, in the teaching process to explore human factors, humanistic education of students. Photography is a technique as well as an art. It is a culture and art linked with science and technology, which cultivates the mind and the soul, contains aesthetic ideal and value [10]. At the university education system, the basic theory of photography, is to improve the students' interest in learning, artistic accomplishment, and to cultivate a refined aesthetic ability and creative thinking skills, since psychological health play a very important role. Living life by capturing wonderful moments, students can develop aesthetic awareness. The student's own artistic, artistic creativity and aesthetic cultivation have been enhanced by practice, step by step. In 
the physics lab, different majors took their colorful image capture photographic works, which greatly improves the physical disciplines of science, fun and practice. Photography and photographic art technology is extended under the optical content extension for knowledge, creativity, artistic sense and skill techniques unlimited vast, helping to improve the overall quality of students, training to adapt to social development talent.

In order to enhance the quality of education for Arts, penetration and cross-disciplinary knowledge, "Introduction to modern science and technology" course have been created. Curriculum around three basic propositions of natural science (the origin and evolution of the universe, the origin of life and evolution, structure and composition of matter) so that students understand the importance of the development of modern science and technology content, the course can enrich and deepen students' knowledge of modern science and technology. Through introduction to cultural and historical background of major scientific discoveries, students get touch with scientific analytical and thinking method. Students are encouraged to respect for facts and science, stay away from superstition. For the modernization of education, Arts and promote cross-disciplinary knowledge and penetration training distinctive graduates.

\section{Expand Teaching Content, Multi-Level to Improve Students' Comprehensive Quality}

To keep with the times, teaching content is adjusted to gradually penetrate general education into talent training. It aims at improving students' overall quality, creativity, and personality. Teaching has been reformed with the concept that "people" should be cultivated to adapt to social development. Philosophy of education has been integrated into teaching them. In the compulsory university physics class, based on the integration of teacher resources, gather course material. Combined with our school characteristics, college physics-related elective courses "Laser applications in agriculture, fiber-optic communications" have been created.

Laser is a human science in the history of a major invention, with unique properties profound impact on contemporary scientific, technical, economic and social development change. Course introduces the principle of laser, laser and selection, laser and breeding, laser and ground preparation, Laser and pest detection, laser and pest control, and weeding laser, laser mutation breeding, laser irradiation from plasmid DNA studies, micro-beam laser transgenic technology research, laser irradiation on seed and seedling ultra-weak luminescence effects, laser technology in agricultural marketing in the security, marketing and landscaping and laser technology trends in agriculture. Enable students to understand the new technology in agriculture is playing an increasingly important role.

In recent years, the rapid development of optical fiber communication greatly influenced all areas of human life. As college students should understand the relevant knowledge, through the introduction of science-type fiber-optic communications theory, optical fiber communication new technologies and trends. So that students can master the theoretical basis, but also integrate theory with practicing in constant contact with new knowledge and keep up with new technology. Elective courses based on compulsory course "university physics" pay attention to the cross-penetration between different disciplines, which expands students' knowledge and promotes their overall development. This way enables students to fully master the knowledge and further broaden the time and space od teaching through multi-channel, multi-form, multi-dimensional, and multi-directional learning. The students' scientific thinking, practice, and innovation ability have been strengthened.

\section{Integration Laboratory Resources, Expanding Experimental Teaching Content, Students Ability to Innovate}

According to the existing conditions Physics Laboratory, integrating faculty and resources in the experimental ultrasonic measurement, optical multi-channel, single photon counting, laser speckle, Raman spectroscopy, based on the creation of " Raman measurements of blood " and" Daqing pipeline corrosion ultrasonic measurement " two innovative experiment for undergraduate school opened a" modern testing technology " elective courses. The combination of theory and experiment focuses on spectroscopy, sensors and other modern means of detection principle of the principles and characteristics of the composition of equipment, training students the integrated use of knowledge and skills to analyze and solve practical problems for the future to solve the practical application of the test lay the foundation for technical problems. Through out with related experimental physics courses and optional courses to improve the utilization of laboratory teaching equipment, educational resources should play a role, but also promote the laboratory construction, better service for teaching, as do the characteristics of a useful attempt. Through elective open, expanding enriched physics teaching, enrich and strengthen the student's knowledge structure, better trained students integrate theory with practice and practical ability, and its overall quality can be improved.

\section{Initial Formation of the Physical Characteristics of the University Curriculum}

University Physics curriculum not only for the scientific quality of the students has a direct effect on students' humanistic qualities also have a significant effect. After years of practice, university physics curriculum is becoming ripe; systems, standards, teaching effect won the praise of teachers and students, and achieved the desired results. Elective open 
series is intended to develop extensive knowledge society, the overall quality is high, with text and other multi-disciplinary knowledge Polytechnic compound talents, optimizing students 'knowledge structure, enhancing students' employability and competitiveness. In addition to meeting the students 'interest in learning, but more important is to guide students broaden range of different disciplines, expanding students' knowledge horizons, enrich students 'learning experience, and improve students' knowledge structure, and ultimately improve the overall quality of students, so as to achieve quality education purposes.

Now, every semester there are students to attend the elective courses we offer. Through years of teaching reform and practice, our own course features are gradually formed: Teaching is set at different levels according to characteristics of students in Agricultural College. Featured by the combination of knowledge, thinking and methods, the content of compulsory course is enriched with application of new physical technology in agriculture, highlighting the principle of high-tech applications. This expands the connotation of teaching and integrates learning knowledge with quality training. Has opened a "laser applications in agriculture", "Technology of photography and photographic art", "Physics and Art", "fiber-optic communications", "modern agricultural testing technology", "Introduction to modern science and technology " and other series of elective courses, broaden the classroom time and space. College physics course has been named the provincial quality courses.

In conclusion, college physical curriculum system with agriculture and forestry universities characteristics has been initially established, which plays an exemplary and popularized role in Chinese congener schools.

\section{Acknowledgment}

This work has been sponsored by Heilongjiang province of China Higher Education Teaching Reform Project (Grant No: JG2013010457; JG2014010911) and Heilongjiang Province of China Higher Education Institute of education science research project (Grant No: 115C-822; HGJXHC 110222) and
Heilongjiang province of china education science of the 12th five-year plan project (Grant No: GBC1212059) and The teaching reform project of Heilongjiang Bayi Agricultural University of China (Grant No: NDJY10103)

\section{References}

[1] Pang Haishao, Huan Xiuhong, General education in China: Review and Expectation [J]. Journal of Higher Education Management, 2016, 10(1): 12-19.

[2] Huang Lihong, General education of physical education of arts in the concept of Applied undergraduate talents cultivation' implementation [J]. Curriculum materials, 2011, 17(3): 93-95.

[3] Shao Huili, Xu Hongxia, Some thoughts on the reform of the university physics general education [J]. Physics Bulletin, 2012(3), 17-18.

[4] Zhu tie Cheng, human values and human cultural construction of physical education [J]. Zhejiang Normal University (Natural Science Edition) 2008, 31 (3): 251-256.

[5] Fang Yun, Wu Fu roots, the expansion of university physics and applications-open elective physics teaching practice research [J]. Guangdong University of Technology (Social Sciences Edition Supplement) 2008, 8 (1): 202-203.

[6] Chen Huiyun, Chen Jian, Some thoughts and exploration of general physics teaching in Public security universities [J]. University Education, 2016, 1(02), 110-111.

[7] Luo Weiyin, Zheng Qingzhang, The concept and practice of physics general education [J]. Physics Bulletin, 2013(1), 9-11.

[8] Wang Le Xin, On connotation-based teaching design of university physics course [J]. Journal of Science of Teachers' College and University2010, 30(3): 112-114.

[9] Shi da Ning, Wu Ping, Yang Yannan, etc., to build innovative intellectual property sensible prominent characteristics of the system engineering physics courses [J]. Physics and Engineering, 2008, 18 (4): 16-19.

[10] Luohui Ting, The role of photography education in college students' quality education [J], China's school education, 2009, 8: 171 . 